\title{
Spatial and temporal distribution of low frequency volcanic earthquakes in the southern Okinawa Trough back-arc basin
}

\author{
Jing-Yi Lin ${ }^{1,2, *}$, Wen-Nan Wu ${ }^{3}$, Chih-Chieh Su ${ }^{4}$, Ching-Hui Tsai ${ }^{2}$, Hsu-Hsiao Sun ${ }^{4}$, Yen-Fu Chen ${ }^{1}$, \\ Shao-Jinn Chin ${ }^{1}$, and Yi-Chin Lin ${ }^{1}$ \\ ${ }^{1}$ Department of Earth Sciences, National Central University, Taoyuan City, Taiwan \\ ${ }^{2}$ Center for Environmental Studies, National Central University, Taoyuan City, Taiwan \\ ${ }^{3}$ College of Oceanography, Hohai University, China \\ ${ }^{4}$ Institute of Oceanography, National Taiwan University, Taipei City, Taiwan
}

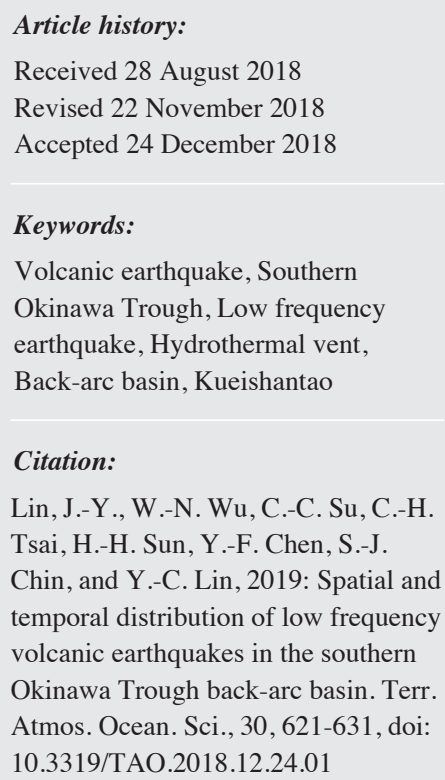

Lin, J.-Y., W.-N. Wu, C.-C. Su, C.-H. Tsai, H.-H. Sun, Y.-F. Chen, S.-J. Chin, and Y.-C. Lin, 2019: Spatial and temporal distribution of low frequency volcanic earthquakes in the southern Okinawa Trough back-arc basin. Terr. Atmos. Ocean. Sci., 30, 621-631, doi: 10.3319/TAO.2018.12.24.01

\begin{abstract}
Located to the south of East China Sea, the Southern Okinawa Trough (SOT) is a back-arc basin, which belongs to the Ryukyu subduction system. SOT is characterized by an active normal faulting system and numerous volcanic outcrops, which could have marine mineral and geo-hazard potential for its nearby areas. By analyzing the data from the inland Central Weather Bureau Seismic Network (CWBSN) stations, we manually exanimated the waveforms of 2263 earthquakes collected from 1991 to the end of 2011 to identify the possible low frequency (LF) volcanic events. In total, $80 \mathrm{LF}$ earthquakes were recognized. An updated relocation seismicity cata$\log$ was used to obtain a more reliable epicenter location. These LF events were mainly located along the central graben of SOT and to the southeast of the Kueishantao (KST) Island. The depths of the LF events are mostly shallower than $15 \mathrm{~km}$ near KST, and become deeper when the hypocenters get closer to the central axis of SOT. The LF earthquakes located near KST have relatively higher tendency to occur in cluster with a time interval of 1 to 4 years and the epicenters show a spatial migration. By comparing the distribution of the LF earthquakes with the available geophysical data, we suggest the major faults in SOT do not only influence the distribution for shallow volcanic bodies, but also confine the area of the deep magmatic activity.
\end{abstract}

\section{INTRODUCTION}

Located to the south of East China Sea, the Southern Okinawa Trough (SOT) is a back-arc basin, which is originated from the subduction of Philippine Sea Plate to the Eurasia Plate (Fig. 1). One of the most obvious features in SOT is the submarine volcanoes (Lee et al. 1980; Liu et al. 1998; Sibuet et al. 1998), an indicator for the presence of hydrothermal vent systems, which infers potential for submarine mineral explorations. On the other hand, submarine volcanic eruptions, occurring more than 100 years ago, have been reported to the south of East China Sea based on the historical records (Chen and Shen 2005). This observation

\footnotetext{
* Corresponding author

E-mail:jylin@ncu.edu.tw
}

also presumes a geo-hazard potential for its nearby areas. However, no further assessment has been conducted due to lack of related information.

Heretofore, several seismic reflection experiments and bathymetry surveys have been conducted to get knowledge about the tectonic environment in SOT (Lee et al. 1980; Liu et al. 1998; Sibuet et al. 1998). The spatial distribution of important geological features, submarine canyons, and volcanic outcrops were well illustrated, which provides a general understanding about the main tectonic processes of the area. However, further investigations, such as seismic and video monitoring, are needed to estimate the intensity of the actual tectonic activities. Lin et al. (2007b, 2009) have revealed the presence of more than 3300 earthquakes during only 10-day recording period by using the data of 15 ocean 
bottom seismometers (OBSs) deployed in SOT. The earthquake activity is characterized by the ceaseless occurrence of small earthquakes, located essentially to the central part of the trough, along the normal faults orientation. In addition, some low frequency events were also reported beneath a volcanic area, inferring the existence of a lower crustal/upper mantle magma chamber. Even though such OBS experiment seems to be a promising method to provide information about the current state of the study area, it is still risky to instruments and high-cost to conduct this kind of operation in such volcanically active areas. Lin et al. (2007a) have used the inland seismic stations data to illustrate a swarm of more than 24 low-frequency earthquakes between the 1 September and 4 September 2006 and show that some submarine volcanoes are still active in SOT. However, limitation in the study duration may not allow monitoring the time evolution of these volcanic activities. In this study, to increase the knowledge about the temporal and spatial resolution for the volcano-related activities in SOT, we analyze the seismic data recorded by the inland Central Weather Bureau Seismic network (CWBSN) in Taiwan. The waveforms and spectrograms were manually examined to determine potential volcanic events occurring in the vicinity of SOT. An update relocation seismicity catalog provides more accurate epicenters for these volcanic events, which allows a reliable spatial distribution analysis. The results bring information for the initial evaluation about hydrothermal potential and geo-hazard risks in the area and its vicinity.

\section{GEOLOGICAL BACKGROUND}

The subduction of the Philippine Sea Plate beneath the Eurasia Plate forms the Ryukyu Arc system, which consists of four distinctive geological units, the Ryukyu Trench, forearc basins, Ryukyu-Arc, and the Okinawa Trough back-arc system (Fig. 1). SOT is the southernmost part of the back-arc basin located in the Eurasia continental crust (Lee et al. 1980; Letouzey and Kimura 1985; Sibuet et al. 1987), to the south of the East China Sea. The area of SOT has been considered to be part of the collisional orogeny, the product of the collision between Luzon arc and Eurasia Plate. Then, with the southward migration of the collisional process, the original orogen collapsed and formed the actual SOT (Teng 1996). Seismic reflection and refraction experiments show that the crustal thickness of the Okinawa Trough becomes thicker from south to north (Lee et al. 1980; Iwasaki et al. 1990; Hirata et al. 1991), 15 - $18 \mathrm{~km}$ for the southern part (Klingelhoefer et al. 2009), whereas 27 - $30 \mathrm{~km}$ for the northern area. The geophysical and bathymetric data indicate that the recent two extensional phases occurred at the Pleistocene (2 - 0.1 Ma) and Pleistocene-Holocene (0.1 - $0 \mathrm{Ma}$ ) with N150 ${ }^{\circ}$ and $\mathrm{N} 170^{\circ}$ direction respectively (Kimura 1985; Miki 1995; Sibuet et al. 1998). Fault mechanisms investigation by using regional (NIED MT) and global (Harvard CMT) moment tensor catalogs also demonstrated an extensional stress field perpendicular to the trough axis (Fournier et al. 2001; Kubo and Fukuyama 2003). In SOT, except for a dominant

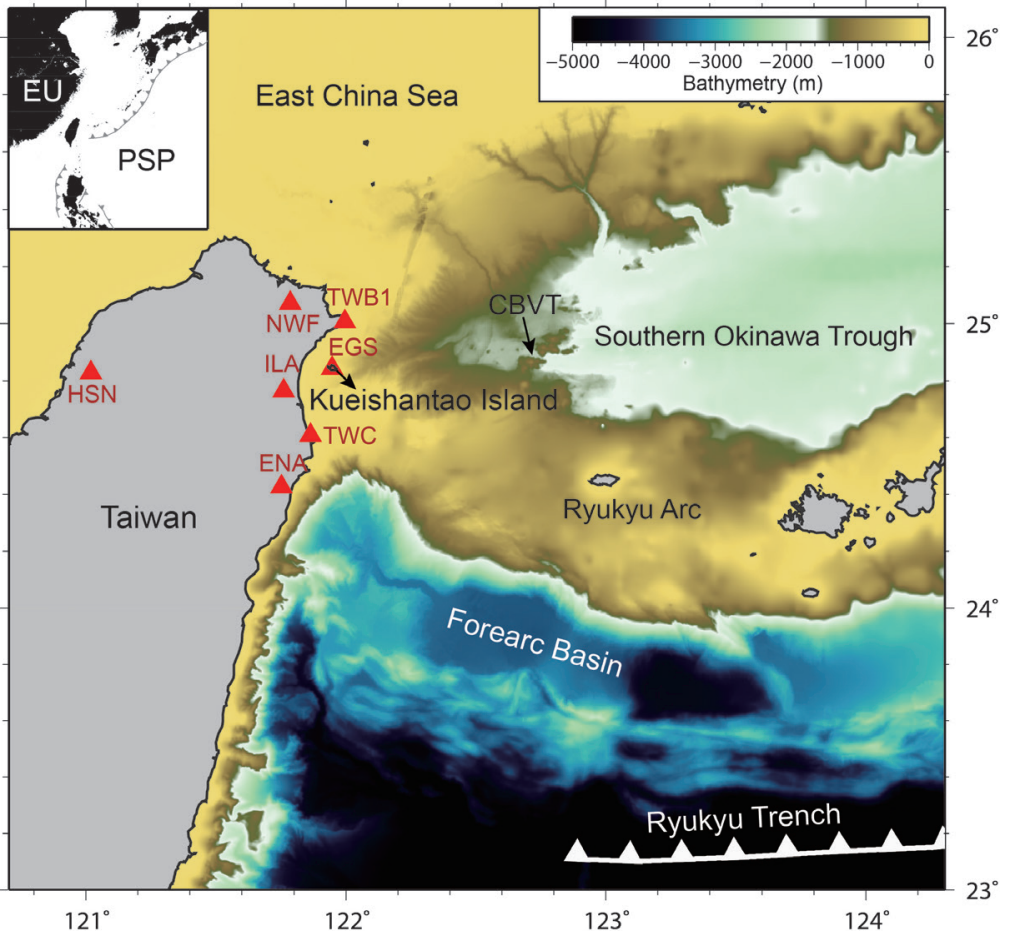

Fig. 1. Geological map and seismic stations (red triangles) used in this study. The inset shows the region tectonic environment. PSP: Philippine Sea Plate; EU: Eurasia Plate. 
normal faulting system, the presence of volcanic intrusions or extrusive seamounts were also illustrated by the seismic profiles and/or high-resolution bathymetry data (Lee et al. 1980; Liu et al. 1998; Sibuet et al. 1998). One area consists of more than 70 submarine volcanoes was reported in the vicinity of $123^{\circ} \mathrm{E}$, named Cross-backarc Volcanic Trail (CBVT) because of its cross-arc pattern (Sibuet et al. 1998; Chung et al. 2000) (Fig. 1). In 2000, the manned deep-sea research submersible Shinkai 6500 (Japan Marine Science and Technology Center) has surveyed one of these submarine volcanos approximately $90 \mathrm{~km}$ from eastern KST for the exploration of hydrothermal vents. Several discernible phenomena were discovered, including a $1-10 \mathrm{~m}$ height chimney, more than $170^{\circ} \mathrm{C}$ hydrothermal emanations temperatures, $\mathrm{pH}$ values of around 4.5 and extensive colonies of organisms (Hsu et al. 2003). Even though only few images have been taken for other hydrothermal-related structures in the north-eastern offshore part of Taiwan, echo sounder and CTD data revealed the presence of hydrothermal plume and vents (Kuo 2001).

KST is a Holocene volcanic islet (latest eruption 7000 years ago) (Liu 1995; Chen et al. 2005; Chiu et al. 2010), which is suggested to be part of western extension of SOT (Liu et al. 1998; Sibuet et al. 1998). A deep magmatic body beneath NE Taiwan was imaged by the regional velocity tomographic result, which was suggested to be source of the KST volcanic system (Lin et al. 2004). A cluster of more than 30 hydrothermal vents is located off the southeastern tip of KST at water depths between 10 and $80 \mathrm{~m}$ (Tarasov et al. 2005; Chiu et al. 2010), revealing its active magmatic process. These submarine hydrothermal vents continuously emit high-temperature fluids discoloring the seawater, which can be easily observed from the sea surface. Konstantinou et al. (2013) analyzed the seismicity recorded by a temporary seismic network deployed both on KST and the coast of northeastern Taiwan. Their results show a tight cluster of events near KST with hypocentral depths between 2.5 and $10 \mathrm{~km}$. The stress inversion based on the focal mechanisms shows a regional NW-SE extensional stress distribution. They also determined one event characterized by a low frequency content $(\sim 10 \mathrm{~Hz})$ and a large non-double-couple component.

\section{DATA}

As the International Seismological Centre (ISC) cata$\log$ comprises the dataset from local networks, we firstly searched for the earthquakes listed in this catalog for the period from 1 January 1991 to 31 December 2013 to have as many events in our study as possible (Fig. 2a). Usually, volcanic chambers often exist along the crust-mantle boundary or are trapped in the crust (e.g., Nicolas et al. 1993; Zhao et al. 2002; Konstantinou et al. 2013), there is few opportunities that the volcano related earthquakes occur at the depth deeper than the subducted slab. Thus, we only selected the earthquakes occurring above the subducted plate for further examination. The slab contours used here were determined from Font et al. (2004) (Fig. 2). In addition, we also eliminated earthquakes with local magnitude smaller than 3 to avoid possible misinterpretations caused by unclear waveform
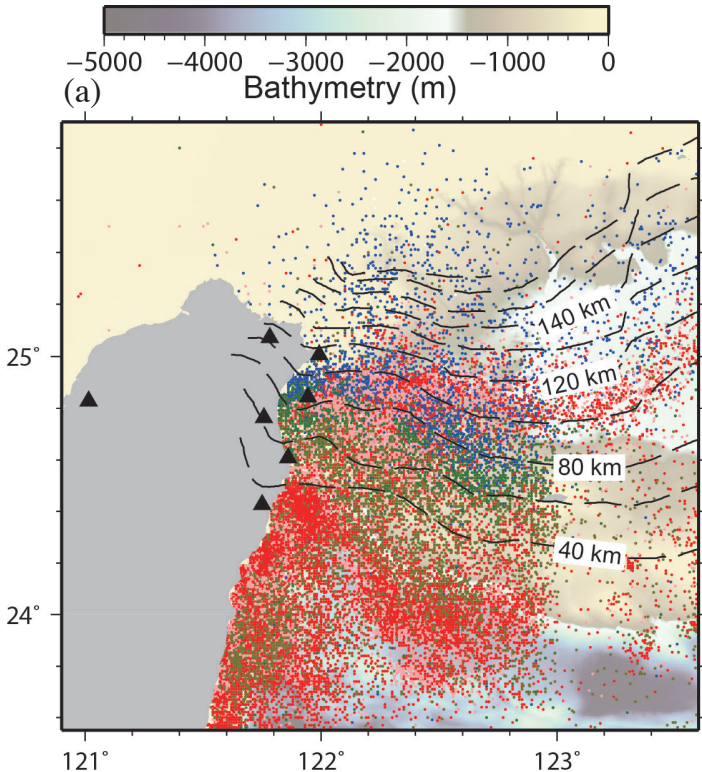

(b)
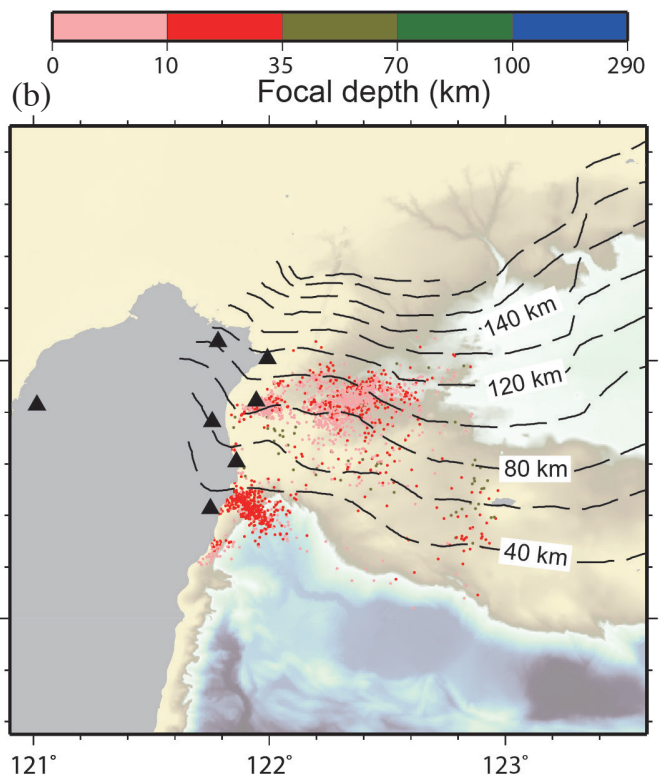

Fig. 2. (a) Earthquakes (color dots) extracted from the International Seismological Center catalog for the period between 1991/01/01 and 2013/12/31; (b) earthquakes (color dots) above the slab, which are with local magnitude larger than 3 and process available waveforms from the Geophysical Dataset Management System (GDMS) (Shin et al. 2013) website in Taiwan (http://gdms.cwb.gov.tw/index.php). Dashed lines show the slab contour extracted from Font et al. (2004). Black triangles are the seismic stations used in this study. 
characteristics. After selecting the events based on the previous criteria, we downloaded the waveforms in sac format for 7 different seismic stations (Fig. 1) of CWBSN from the Geophysical Dataset Management System (GDMS) website in Taiwan (http://gdms.cwb.gov.tw/index.php) (Shin et al. 2013). However, there was a serious lack of waveform data after 2012 at the moment. Thus, we reduced our analysis period to be from 1991 - 2011. In total, the seismograms of 2263 earthquakes with magnitude $\left(\mathrm{M}_{\mathrm{L}}\right)$ larger than 3 were collected in the 20-year time span (Fig. 2b). We can notice that almost all the selected earthquakes are located to the west of $123^{\circ} \mathrm{E}$ (Fig. 2b), which is due to the limitation of seismic stations distribution in Taiwan. Overall, the study area is within $119-123^{\circ} \mathrm{E}$ and $23.86-25.30^{\circ} \mathrm{N}$, which includes SOT, part of the Ryukyu Arc and continental shelf. Nevertheless, the epicenter in the ISC catalog was determined based on a 1-D velocity model, which may not precise enough to perform spatial analyses for the earthquakes distribution. Wu et al. (2008) developed a relocation procedure on the earthquake catalog of CWBSN. They incorporated a large dataset and adopted a 3-D velocity model for earthquakes relocation in their work. Moreover, they added the arrivals of 18 Japan Meteorological Agency (JMA) stations deployed in the southern Ryukyu Island to increase the ray path coverage for eastern Taiwan offshore events, which improve significantly the accuracy in earthquake locations of the area. This relocation seismicity catalog is continuously updated (Wu et al. 2013). Therefore, we use the epicenters of the catalog for further discussion.

Seismic events at volcanoes could have variable waveform characteristics (Chouet 1996; McNutt 2005). Generally, they are classified into 3 types: Long-period, Volcanotectonic, and hybrid events (McNutt 2005). Volcano-tectonic earthquake is generated by the movement of magma, which results in pressure changes in the rock and causes failure. The waveform of Volcano-tectonic event is similar to that of an ordinary tectonic earthquake, with high frequency content and clear $\mathrm{P}$ - and $\mathrm{S}$-wave arrivals. Long-period event is also called low frequency (LF) event because of its concentration of spectral energy at a relatively lower frequency band. This kind of event is usually linked to different magmatic and hydrothermal processes and is considered as slow-rupture failure in unconsolidated volcanic materials (Bean et al. 2014). The S-wave is often unclear for the LF events due to this particular mechanism. Hybrid earthquakes comprise the former two types of signals, having high-frequency onsets and low-frequency coda. The mixed characteristics of this type signal was suggested to have brittle-failure origin and the low-frequency content could be the influences of low rupture velocities and/or strong path effect (Harrington and Brodsky 2007). In our study, LF events are of a particular interest as they are often associated with fluid/magma movement in the volcano. Thus, for the selection of magmagenerated events, the waveform characteristics for the LF events were used in the study, which are no clear S-wave and low-frequency energy content. In addition to visually examining the waveforms, we also conducted a spectral analysis in order to investigate possible differences in their frequency content.

On the other hand, propagation effects could occur in volcanic areas. The existence of any anomalous structures between the source and receiver can potentially modify the waveform and change its characteristics. As the structures between the source and receiver are unknown and all the seismic station are located only on one side of the sources, this problem could still exist even though all available stations are examined. For this purpose, we compare the waveform recorded by the same station but from two different nearby sources to avoid mis-determination of the LF events. Similar source-receiver location should have comparable ray path effect. Thus, any variance between the waveform of these two nearby sources should result from the source effect itself. This operation was systematically performed when a LF event was determined. The earthquakes located less than $10 \mathrm{~km}$ in horizontal distance and $5 \mathrm{~km}$ in depth from this event were verified to avoid the cases caused by the path effect. Figure 3 shows two examples of waveforms and spectrograms generated by two nearby sources and recorded by the same station. One example is near KST, whereas the other is located near the central graben area of SOT. Distinctive patterns were observed both for the waveforms and spectrograms. Events with no clear S-wave waveform are usually characterized by low frequency content spectrogram (Figs. 3b and e). A dominant frequency of approximately less than $4 \mathrm{~Hz}$ could be observed. In contrast, the frequency band of the other earthquake (Figs. $3 c$ and f) is dominated by approximately $5-10 \mathrm{~Hz}$. In addition, the LF earthquakes have longer duration than that of the tectonic earthquakes, which is consistent with the results already reported near this volcanic area (Lin et al. 2007a). Even though clear definition about these LF earthquakes was given, ambiguity could still happen frequently when we determine the LF events by using the seismogram and spectral characteristics. For example, a mix of noise and signal usually could result in a more complicate waveform, or the main energy for the spectrogram concentrates at a frequency in between the low and high values. In these cases, we eliminated these uncertain events to avoid any possible misinterpretation in our study.

\section{RESULTS AND DISCUSSION}

Finally, 82 events characterized with low frequency content, no clear S-wave waveform and relatively longer duration have been identified after visually checking the waveforms and spectrograms of the 2263 earthquakes. However, two earthquakes were not found in the update relocation catalog (Wu et al. 2008). Therefore, only 80 events were discussed in the following sessions (Figs. 4, 5, and 6). 


\subsection{Spatial and Magnitude Distribution}

The $80 \mathrm{LF}$ earthquakes determined from our study are suggested to be volcano-related low frequency events. They are mainly located in two areas: (1) to the east of $122.2^{\circ} \mathrm{E}$, along the central graben of SOT and (2) to the west of $122.05^{\circ} \mathrm{E}$, to the southeast of KST (Fig. 4a). Only a few events were observed for the CBVT area, where the volcanic topographic characteristics is remarkable. This result should be caused by the limitation of the inland network capacity. As all the used seismic station are located inland, the number of reported earthquakes and available waveforms decrease rapidly with the distance from the land area. Thus, we would not discuss about the CBVT area in our study. However, the gap between 122.05 and $122.2^{\circ} \mathrm{E}$ should indeed exist, where the lack of large volcanic earthquakes could be confirmed. Depth of these LF events ranges principally from 0.32 - $21.66 \mathrm{~km}$ (Fig. 4). The events around KST generally have a relatively shallower depth of about $0-14 \mathrm{~km}$, whereas the depth increase for those located along the central graben of SOT. The crustal thickness of SOT has been determined between 15 and $18 \mathrm{~km}$ (Lee et al. 1980; Iwasaki et al. 1990; Hirata et al. 1991). Therefore, the LF volcanic earthquakes identified in our study should have origins within or at the bottom of the crust. General concepts suggest the underground magma originated from mantle rises and cumulates in the upper crust to form a magma reservoir. This depth distribution shows agreement with the typical idea. Relatively shallow LF earthquakes are located along the central axis for the central graben cluster (red and orange
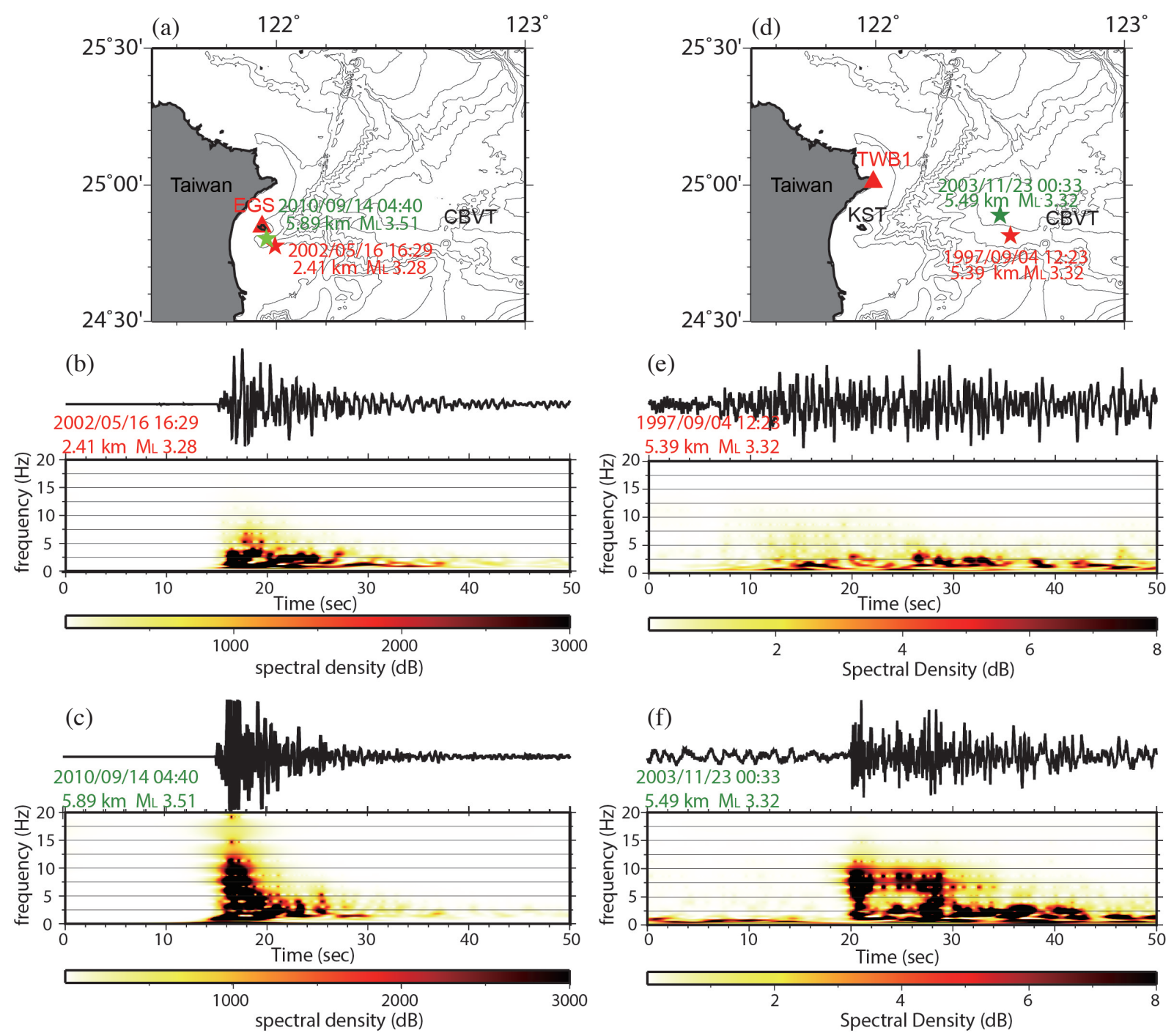

Fig. 3. Examples of vertical velocity waveform and corresponding spectrogram for two events located nearby and recorded by the same station. (a) to (c) are the example from the earthquakes occurred near the Kueishantao (KST) Island area, whereas (d) to (f) for the earthquakes in the central graben of the Southern Okinawa Trough (SOT) area. (a) and (d) show the positions of the two nearby earthquakes. Green and red star indicates the normal tectonic and low frequency (LF) earthquake, respectively. Red triangle shows the station where the waveform was recorded. The corresponding waveform and spectrogram are plotted in (b) and (e) for the LF events and in (c) and (f) for the normal tectonic earthquakes. 


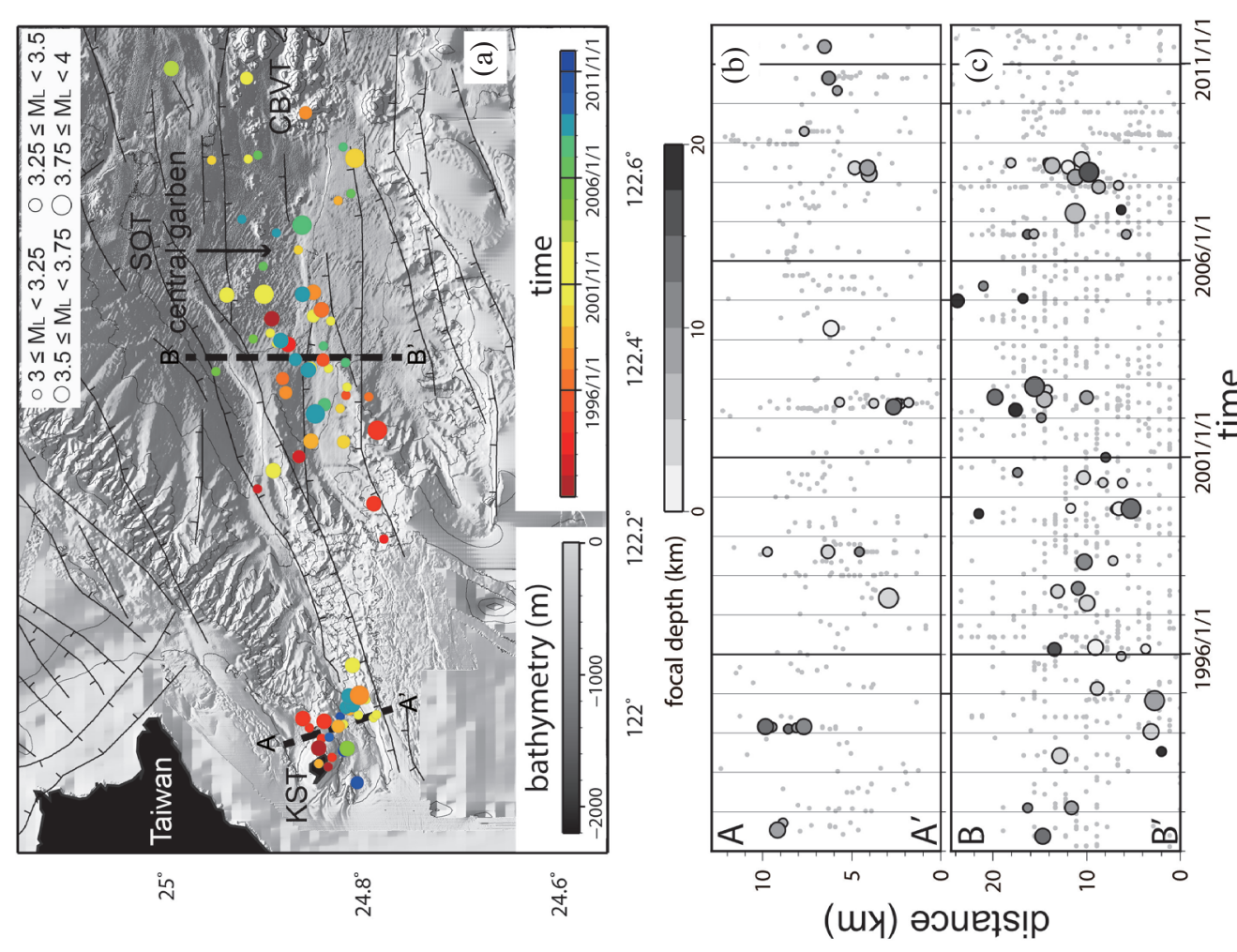

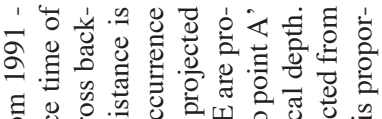
है

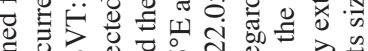

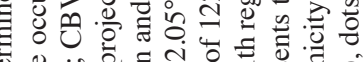

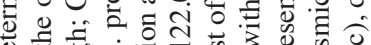
पू

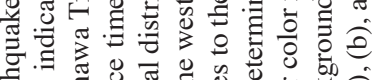

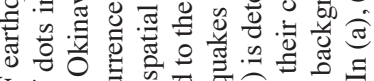

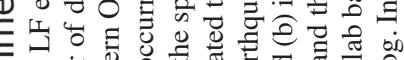

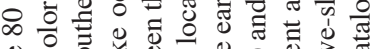

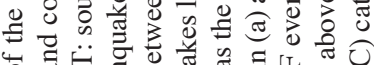

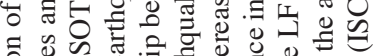

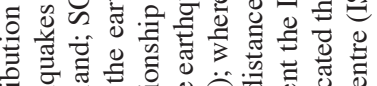

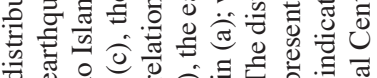

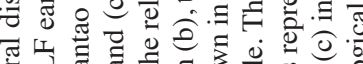

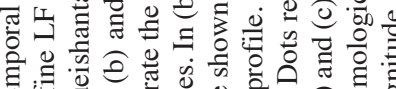

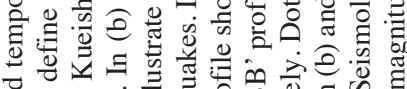

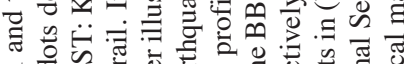
霖

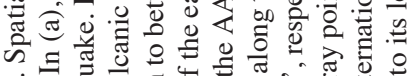

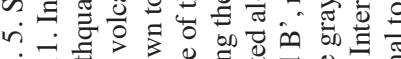

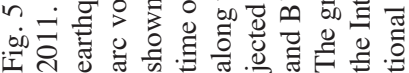

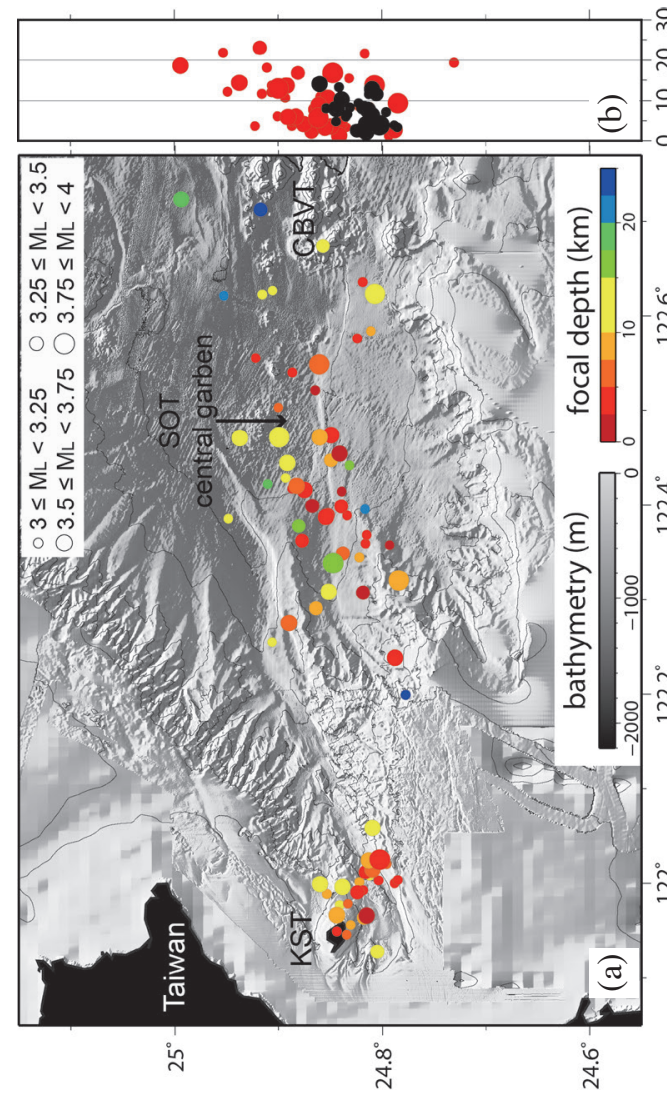

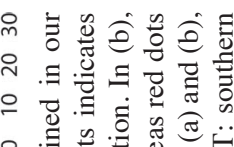

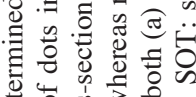

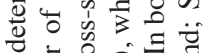

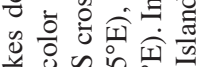
- 势更之

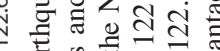
का

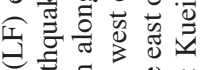

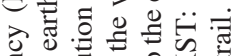
记

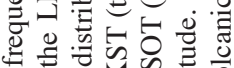
30 论

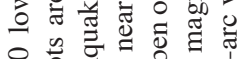
$\infty$ 过氖总焉

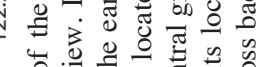
o

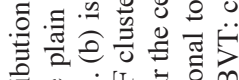

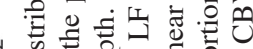

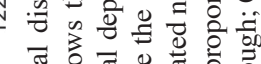

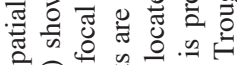
की

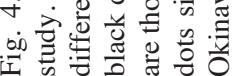




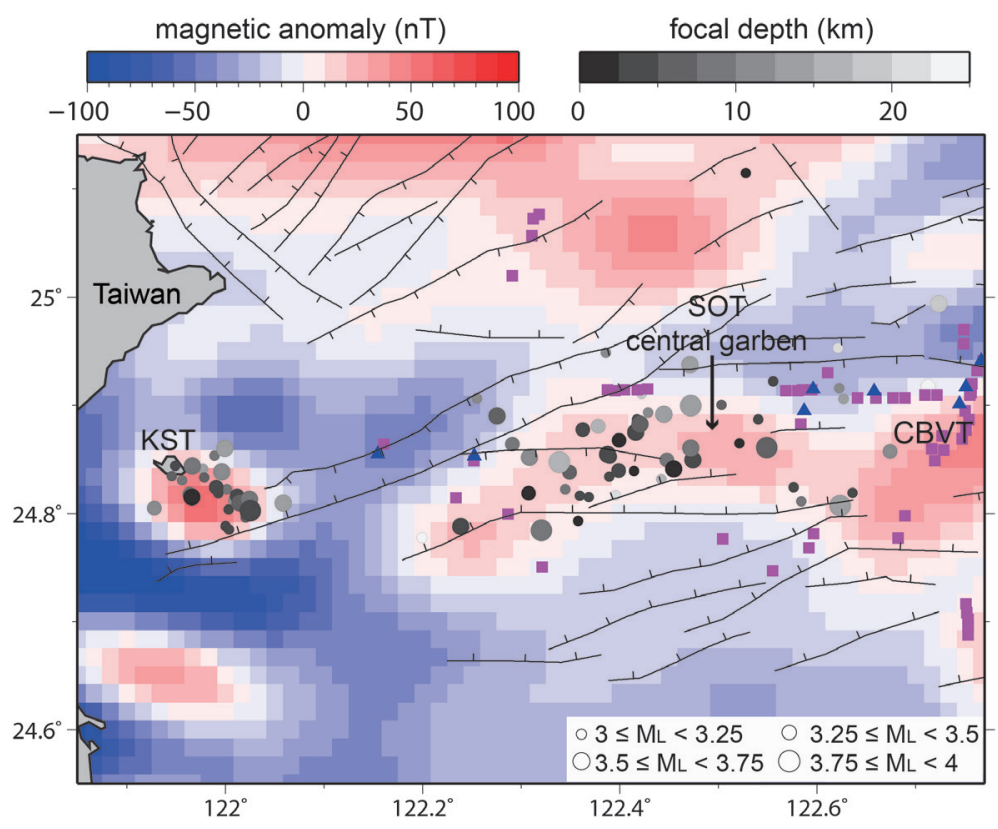

Fig. 6. Magnetic anomalies (Hsu et al. 1998), major normal faults determined from seismic data (Sibuet et al. 1998) and the LF earthquakes distribution. Blue triangles and purple rectangles show the position of the volcanic outcrops and intrusion (Tsai 1999; Lee et al. 2004), respectively. Dots are the LF earthquakes and color of dots represents the depth. Dots size is proportional to its local magnitude. KST: Kueishantao Island; SOT: southern Okinawa Trough; CBVT: cross back-arc volcanic trail.

dots in Fig. 4a). This distribution may suggest that the magma chamber should be the closest to the seafloor along the topographic central depression, where the back-arc opening process was suggested to be the most active. The discovery of non-volcanic LF earthquakes has been reported for the Ryukyu Trench and Nankai Trough (Ide et al. 2007; Ando et al. 2012; Nakamura and Sunagawa 2015) areas, which are generally considered to be generated by the shear slip (Ide et al. 2007) and/or hydro-fracturing (Seno and Yamasaki 2003) processes along the plate interface. Even though non-volcanic LF events share similar frequency content as the volcanic events studied in our area, they have distinct sources areas. All the LF earthquakes observed in our result are located shallower than $25 \mathrm{~km}$ at depth, where the slab contour is about $80-120 \mathrm{~km}$. Therefore, the fact that we only discuss about the volcanic activity without considering the non-volcanic component should be justified. With regard to the magnitude of these LF earthquakes, the value is less than 4. No earthquakes with larger magnitude was revealed. Previous studies showed that volcanic earthquakes are smaller in size (Chouet and Matoza 2013). Similar result was reported in our study. Otherwise, we do not observe any relationship between local magnitude and spatial location of these LF earthquakes.

\subsection{Temporal Distribution}

Figure 5a shows the temporal distribution of the LF volcanic events. Color of dots shows its occurrence time.
We found that the events occurred along the central graben and near KST have different temporal distribution characteristics. For the former group, the events having occurrence time close to each other generally do not have obvious spatial relationship. It means that two events occurred almost simultaneously could be located far from each other (dots with same color in Fig. 5a). In contrast, the neighboring events usually have a closer occurrence time for the latter KST group. Figure $5 b$ demonstrated even a stronger temporal relationship for the events occurred in KST. Compared with the events along the central graben (to the east of $122.1^{\circ} \mathrm{E}$ ) (Fig. $5 \mathrm{c}$ ), the events near KST (to the west of $122.05^{\circ} \mathrm{E}$ ) obviously tend to occur temporally in cluster. The cluster of several LF events only occurred in 1991, 1994, $1997,1998,2002,2004,2008$, and 2010 during the approximately 20 years recording period (Fig. $5 \mathrm{~b}$ ). The interval between each cluster are not regular, usually between 1 and 4 years. This kind of LFs cluster could also be observed for the SOT central graben area, particularly distinct in 1999, 2002, and 2008. This phenomenon is in consistency with the observation reported for other volcanic areas that volcanic earthquakes usually have a time clustering characteristic (e.g., Codano et al. 1997; Eggert and Walter 2009). This concentration of volcanic earthquakes are usually linked to the magma dike injection or migration process during some active phases (e.g., Dziak and Fox 1999). In Figs. 5b and c, we also plotted the background seismicity reported by the ISC (gray points in Figs. 5b and c). It appears that the occurrence of the LFs for the KST corresponds very well to the 
tectonic earthquakes swarm. However, similar relation between the LFs and the background seismicity was only observed in 2008 for the SOT central graben area. It is interesting to notice that when there is a cluster occurring near KST, events with relatively larger magnitude appear also along the central graben. When there is no event observed in the KST group, only events with magnitude smaller than about $\mathrm{M}_{\mathrm{L}} 3.5$ appear for the central graben area, such as the cases occurred during the period between 1992 and 1993, 1995 and 1996, 1999 and 2002, 2005 and 2006 (Figs. 5b and c). The tectonic activity for both the KST and SOT is originated and influenced by the Okinawa Trough back-arc basin process. Thus, the time coincidence of the occurrence of LF cluster at both KST and SOT central graben may suggest that the LF earthquake activity near KST and along the SOT central graben area have the same driven mechanism. When the magma supply is large enough, both areas could have an amplified volcanic activities and relatively larger events could occur simultaneously. Furthermore, a systematic migration of LF earthquakes with time was observed for KST. The events seem to migrate from the northwest to the south-east, then back to the north-western part (Fig. 5b). The migration of the volcanic earthquakes with time has been reported in the literature, which is often linked to the magma supply process for a volcano (e.g., Rubin et al. 1998; Dziak and Fox 1999; Battaglia et al. 2005). However, investigation with a higher resolution, such as monitoring with a denser seismic network, is required for further information about the detailed process.

\subsection{Comparison with Other Geophysical and Geological Data}

By comparing the position of the LF earthquakes with the magnetic anomaly map, a good correlation was found (Fig. 6). Most of the LF earthquakes are located in the area where positive magnetic anomalies appear. Even though the LF earthquakes are located at relatively deeper depth, the igneous rock could be formed at shallower depth when the magma moves upward and the ambient temperature decreases. Thus, the good correlation between the LF earthquakes and positive magnetic anomalies should be understandable. To the north of SOT, the continental slope is also characterized by a high magnetic anomaly. However, very few LF events were discovered in that area. We suggest that the magnitude of the volcanic activities for that area may be too small to be recorded. Otherwise, we have limited data to provide any other information.

The presence of normal faults in SOT was widely reported (Lee et al. 1980; Sibuet et al. 1998; Fournier et al. 2001; Lin et al. 2009). We find that the LF events along the central graben area were bounded by the major normal faults, a southward dipping fault plane to their north and a northward dipping fault plane to their south (Fig. 6). For the
KST area, some of events area also located within the central depression of a normal fault system. The major faults confine not only the LF earthquakes, but also the central depression area of SOT (Fig. 5a), where the extensional tectonic process was supposed to be the most active. Thus, this good agreement may indicate that the volcanic activities should be controlled by regional tectonic structures. It is interesting to notice that the volcanic outcrops and intrusion recognized from marine geophysical data (Tsai 1999; Lee et al. 2004) are not located right over these LF earthquakes but surround them (Fig. 6). General concepts and models consider volcanic dome as the surface expression of its underneath magma chamber (e.g., Walker 1989; Head and Wilson 1992) where the LF earthquakes should occur. However, former studies show that part of the volcanic rocks exist below the faults to form intrusive rocks, others have risen along fault zones, and forms a submarine volcano (e.g., Sibuet et al. 1998; Rowland and Sibson 2004). Thus, instead of being influenced by the deep magmatic sources, location of volcanism near the seafloor should be mainly controlled by the extensional faults in SOT.

The first discovery of the LF earthquakes along SOT was reported by Lin et al. (2007a). A volcanic swarms consist of at least 24 earthquakes with magnitudes between 2.2 and 3.5 was identified by the land seismic stations data within two days in early September 2006 (Lin et al. 2007a). In our study, two LF earthquakes were reported during this period (Fig. 5). As we only selected earthquakes with local magnitude larger than 3 . The lack of comparable events with this previous work should be due to the elimination of earthquakes with smaller magnitude. After all, our study still does not miss the major events reported by Lin et al. (2007a), which infers that our result should be robust. Konstantinou et al. (2013) analyzed the seismicity recorded by a temporary seismic network deployed both on KST and the coast of northeastern Taiwan during 2008. A momenttensor inversion based on a $\mathrm{M}_{\mathrm{L}} 4.4$ earthquake occurred to the southeast of KST exhibited a low frequency content $(\sim 10 \mathrm{~Hz})$ and a large non-double-couple component suggesting fluid involvement at its source. The position of this LF earthquake coincides with the cluster of LF earthquakes observed in our study, which confirms a relatively active magmatic process to the southeast of KST. However, Konstantinou et al. (2013) also observed a swarm of LF earthquakes located to the northeast of KST. We did not observe any LF events for this area. The spectrogram of the LF earthquakes they determined showed a principle frequency content of $1-6 \mathrm{~Hz}$, and the S-wave could still be identified. Thus, the cluster determined in their study, to the northeast of KST, should have a volcano-tectonic origin, which is not studied in this work. Otherwise, in our study, the selection of earthquakes with magnitude larger than 3 may reduce the uncertainty for the waveform determination, but this threshold could also limit our understanding about the volcanic 
activity with relatively smaller magnitude. More detailed information with regard to the distribution of different type of volcanic earthquakes should be performed with the deployments of a denser network in the future.

\section{CONCLUSION}

In the aim of increasing the understanding about the temporal and spatial distribution characteristics for the volcano-related activities in SOT, we analyze the seismic data recorded by the inland CWBSN in Taiwan. The waveforms and spectrograms of 2263 earthquakes collected from 1991 to the end of 2011 were manually examined and 80 possible volcanic events were identified. To insure that the LF waveform was not caused by the path or site effect, the waveform of two nearby sources recorded by the same station were systematically verified. Furthermore, we obtained the epicenters from an update seismicity catalog which allows to perform a more reliable analysis for the spatial distribution of these volcano-related events. Unprecedented understanding about the volcanic activities in SOT were revealed. The result shows that the LF events were mainly located along the central graben of SOT and to the southeast of the KST Island. The depths of LF events near KST are mostly shallower than $14 \mathrm{~km}$, and become deeper to about $22 \mathrm{~km}$ when the hypocenters get closer to the central axis of SOT. The central axis of the back-arc spreading center, bounded by well-developed normal faults system, usually has the most active extensional effect. The concentration of most LF events along the central depression suggests that the occurrence of volcanic earthquakes should be controlled by the tectonic structures and relatively higher geothermal potential could be found along the central graben area. The temporal distribution of LF events near KST demonstrated a periodic occurrence pattern, which was reported for the first time in the area. The LF events migrated with time, which is generally linked to the magma supply process. In this case, we may quantify the magnitude of the magma supply system and estimate the potential for a volcanic explosion in the future. By comparing the distribution of LF earthquakes with the distribution of volcanic outcrops and intrusion determined from the former studies, we found that all these volcanic products on the seabed (i.e., volcanic outcrops and intrusion) are not located on the top of these LF earthquakes but surround them, along some normal faults. We suggest that instead of being the surface expression of the deep volcanic activity, the volcanism near the sea floor is mainly controlled by the tectonic structures. Overall, our result provides the generally volcanic activity patterns and characteristics for the SOT area. Detailed processes may still depend on the application of high resolution experiments in the future.

Acknowledgements We thank the Geophysical Database Management System (GDMS), developed by the Central
Weather Bureau (CWB) of Taiwan for providing highquality seismic data. All figures were made by the Generic Mapping Tools (Wessel and Smith 1998). This research was supported by the Central Weather Bureau of Taiwan with grant MOTC-CWB-107-E-05, MOTC-CWB-108-E-05, and by the Ministry of Science and Technology, Taiwan, under contract MOST-107-2116-M-008-017. Two anonymous reviewers are acknowledged for their helpful comments.

\section{REFERENCES}

Ando, M., Y. Tu, H. Kumagai, Y. Yamanaka, and C. H. Lin, 2012: Very low frequency earthquakes along the Ryukyu subduction zone. Geophys. Res. Lett., 39, doi: 10.1029/2011GL050559. [Link]

Battaglia, J., V. Ferrazzini, T. Staudacher, K. Aki, and J.-L. Cheminée, 2005: Pre-eruptive migration of earthquakes at the Piton de la Fournaise volcano (Réunion Island). Geophys. J. Int., 161, 549-558, doi: 10.1111/j.1365246X.2005.02606.x. [Link]

Bean, C. J., L. De Barros, I. Lokmer, J.-P. Métaxian, G. O'Brien, and S. Murphy, 2014: Long-period seismicity in the shallow volcanic edifice formed from slow-rupture earthquakes. Nat. Geosci., 7, 71-75, doi: 10.1038/ ngeo2027. [Link]

Chen, C.-H. and J. J.-S. Shen, 2005: A refined historical record of volcanic eruptions around Taiwan: Tectonic implications in the arc-continent collision area. Terr. Atmos. Ocean. Sci., 16, 331-343, doi: 10.3319/ TAO.2005.16.2.331(TT). [Link]

Chen, C.-T. A.,Z.Zeng, F.-W. Kuo, T. F. Yang, B.-J. Wang, and Y.-Y. Tu, 2005: Tide-influenced acidic hydrothermal system offshore NE Taiwan. Chem. Geol., 224, 69-81, doi: 10.1016/j.chemgeo.2005.07.022. [Link]

Chiu, C.-L., S.-R. Song, Y.-C. Hsieh, and C.-X. Chen, 2010: Volcanic characteristics of Kueishantao in northeast Taiwan and their implications. Terr. Atmos. Ocean.Sci., 21, 575-585, doi: 10.3319/TAO.2010.02.22.02(TH). [Link]

Chouet, B. A., 1996: Long-period volcano seismicity: Its source and use in eruption forecasting. Nature, 380, 309-316, doi: 10.1038/380309a0. [Link]

Chouet, B. A. and R. S. Matoza, 2013: A multi-decadal view of seismic methods for detecting precursors of magma movement and eruption. J. Volcanol. Geotherm. Res., 252, 108-175, doi: 10.1016/j.jvolgeores.2012.11.013. [Link]

Chung, S. L., S. L. Wang, R. Shinjo, C. S. Lee, and C. H. Chen, 2000: Initiation of arc magmatism in an embryonic continental rifting zone of the southernmost part of Okinawa Trough. Terr. Nova, 12, 225-230, doi: 10.1046/j.1365-3121.2000.00298.x. [Link]

Codano, C., M. L. Alonzo, and G. Vilardo, 1997: Multifractal approach to time clustering of earthquakes. 
Application to Mt. Vesuvio seismicity. Pure Appl. Geophys., 149, 375-390, doi: 10.1007/s000240050031. [Link]

Dziak, R. P. and C. G. Fox, 1999: The January 1998 earthquake swarm at Axial Volcano, Juan de Fuca Ridge: Hydroacoustic evidence of seafloor volcanic activity. Geophys. Res. Lett., 26, 3429-3432, doi: 10.1029/1999GL002332. [Link]

Eggert, S. and T. R. Walter, 2009: Volcanic activity before and after large tectonic earthquakes: Observations and statistical significance. Tectonophysics, 471, 14-26, doi: 10.1016/j.tecto.2008.10.003. [Link]

Font, Y., H. Kao, S. Lallemand, C.-S. Liu, and L.-Y. Chiao, 2004: Hypocentre determination offshore of eastern Taiwan using the Maximum Intersection method. Geophys. J. Int., 158, 655-675, doi: 10.1111/j.1365246X.2004.02317.x. [Link]

Fournier, M., O. Fabbri, J. Angelier, and J. P. Cadet, 2001: Regional seismicity and on-land deformation in the Ryukyu arc: Implications for the kinematics of opening of the Okinawa Trough. J. Geophys. Res., 106, 13751-13768, doi: 10.1029/2001JB900010. [Link]

Harrington, R. M. and E. E. Brodsky, 2007: Volcanic hybrid earthquakes that are brittle-failure events. Geophys. Res. Lett., 34, doi: 10.1029/2006GL028714. [Link]

Head, J. W. and L. Wilson, 1992: Magma reservoirs and neutral buoyancy zones on Venus: Implications for the formation and evolution of volcanic landforms. J. Geophys. Res., 97, 3877-3903, doi: 10.1029/92JE00053. [Link]

Hirata, N., H. Kinoshita, H. Katao, H. Baba, Y. Kaiho, S. Koresawa, Y. Ono, and K. Hayashi, 1991: Report on DELP 1988 cruises in the Okinawa Trough: Part 3. Crustal structure of the southern Okinawa Trough. Bull. Earthquake Res. Inst. Univ. Tokyo, 66, 37-70.

Hsu, S.-C., F.-J. Lin, W.-L. Jeng, Y.-C. Chung, and L.-M. Shaw, 2003: Hydrothermal signatures in the southern Okinawa Trough detected by the sequential extraction of settling particles. Mar. Chem., 84, 49-66, doi: 10.1016/S0304-4203(03)00102-6. [Link]

Hsu, S.-K., C.-S. Liu, C.-T. Shyu, S.-Y. Liu, J.-C. Sibuet, S. Lallemand, C. Wang, and D. Reed, 1998: New gravity and magnetic anomaly maps in the TaiwanLuzon region and their preliminary interpretation. Terr. Atmos. Ocean. Sci., 9, 509-532, doi: 10.3319/ TAO.1998.9.3.509(TAICRUST). [Link]

Ide, S., D. R. Shelly, and G. C. Beroza, 2007: Mechanism of deep low frequency earthquakes: Further evidence that deep non-volcanic tremor is generated by shear slip on the plate interface. Geophys. Res. Lett., 34, doi: 10.1029/2006GL028890. [Link]

Iwasaki, T., N. Hirata, T. Kanazawa, J. Melles, K. Suyehiro, T. Urabe, L. Möller, J. Makris, and H. Shimamura, 1990: Crustal and upper mantle structure in the Ryukyu Island Arc deduced from deep seismic sounding.
Geophys. J. Int., 102, 631-651, doi: 10.1111/j.1365246X.1990.tb04587.x. [Link]

Kimura, M., 1985: Back-arc rifting in the Okinawa Trough. Mar. Petrol. Geol., 2, 222-240, doi: 10.1016/02648172(85)90012-1. [Link]

Klingelhoefer,F., C.-S.Lee, J.-Y.Lin, and J.-C. Sibuet, 2009: Structure of the southernmost Okinawa Trough from reflection and wide-angle seismic data. Tectonophysics, 466, 281-288, doi: 10.1016/j.tecto.2007.11.031. [Link]

Konstantinou, K., C.-Y. Pan, and C.-H. Lin, 2013: Microearthquake activity around Kueishantao island, offshore northeastern Taiwan: Insights into the volcanotectonic interactions at the tip of the southern Okinawa Trough. Tectonophysics, 593, 20-32, doi: 10.1016/j. tecto.2013.02.019. [Link]

Kubo, A. and E. Fukuyama, 2003: Stress field along the Ryukyu Arc and the Okinawa Trough inferred from moment tensors of shallow earthquakes. Earth Planet. Sci. Lett., 210, 305-316, doi: 10.1016/S0012821X(03)00132-8. [Link]

Kuo, F.-W., 2001: Preliminary investigation of the hydrothermal activities off Kueishantao Island. Master Thesis, Institute of Marine Geology and Chemistry, National Sun Yat-sen University, Kaohsiung, Taiwan, 90 pp. (in Chinese with English abstract)

Lee, C.-S., G. G. Shor, L. D. Bibee, R. S. Lu, and T. W. Hilde, 1980: Okinawa Trough: Origin of a back-arc basin. Mar. Geol., 35, 219-241, doi: 10.1016/00253227(80)90032-8. [Link]

Lee, Y., C. Tsai, and C. Lee, 2004: The study of active submarine volcanoes and hydrothermal vents in the southernmost part of Okinawa Trough. American Geophysical Union, Fall Meeting, abstract id. S41A-0939.

Letouzey, J. and M. Kimura, 1985: Okinawa Trough genesis: Structure and evolution of a backarc basin developed in a continent. Mar. Petrol. Geol., 2, 111-130, doi: 10.1016/0264-8172(85)90002-9. [Link]

Lin, C. H., L. W. Hsu, M. Y. Ho, T. C. Shin, K. J. Chen, and Y. H. Yeh, 2007a: Low-frequency submarine volcanic swarms at the southwestern end of the Okinawa Trough. Geophys. Res. Lett., 34, doi: 10.1029/2006GL029207. [Link]

Lin, J.-Y., S.-K. Hsu, and J.-C. Sibuet, 2004: Melting features along the western Ryukyu slab edge (northeast Taiwan): Tomographic evidence. J. Geophys. Res., 109, doi: 10.1029/2004JB003260. [Link]

Lin, J.-Y., J.-C. Sibuet, C.-S. Lee, S.-K. Hsu, and F. Klingelhoefer, 2007b: Origin of the southern Okinawa trough volcanism from detailed seismic tomography. J. Geophys. Res., 112, doi: 10.1029/2006JB004703. [Link]

Lin, J.-Y., J.-C. Sibuet, C.-S. Lee, S.-K. Hsu, F. Klingelhoefer, Y. Auffret, P. Pelleau, J. Crozon, and C.-H. Lin, 
2009: Microseismicity and faulting in the southwestern Okinawa Trough. Tectonophysics, 466, 268-280, doi: 10.1016/j.tecto.2007.11.030. [Link]

Liu, C.-C., 1995: The Ilan plan and the southwestward extending Okinawa Trough. J. Geol. Soc. China, 38, 229-242.

Liu, C.-S., S.-Y. Liu, S. E. Lallemand, N. Lundberg, and D. L. Reed, 1998: Digital elevation model offshore Taiwan and its tectonic implications. Terr. Atmos. Ocean. Sci., 9, 705-738, doi: 10.3319/ TAO.1998.9.4.705(TAICRUST). [Link]

McNutt, S. R., 2005: Volcanic seismology. Annu. Rev. Earth Planet. Sci., 33, 461-491, doi: 10.1146/annurev. earth.33.092203.122459. [Link]

Miki, M., 1995: Two-phase opening model for the Okinawa Trough inferred from paleomagnetic study of the Ryukyu arc. J. Geophys. Res., 100, 8169-8184, doi: 10.1029/95JB00034. [Link]

Nakamura, M. and N. Sunagawa, 2015: Activation of very low frequency earthquakes by slow slip events in the Ryukyu Trench. Geophys. Res. Lett., 42, 1076-1082, doi: 10.1002/2014GL062929. [Link]

Nicolas, A., C. Freydier, M. Godard, and A. Vauchez, 1993: Magma chambers at oceanic ridges: How large? Geology, 21, 53-56, doi: 10.1130/0091-7613(1993)021<00 53:MCAORH>2.3.CO;2. [Link]

Rowland, J. V. and R. H. Sibson, 2004: Structural controls on hydrothermal flow in a segmented rift system, Taupo Volcanic Zone, New Zealand. Geofluids, 4, 259-283, doi: 10.1111/j.1468-8123.2004.00091.x. [Link]

Rubin, A. M., D. Gillard, and J. L. Got, 1998: A reinterpretation of seismicity associated with the January 1983 dike intrusion at Kilauea Volcano, Hawaii. J. Geophys. Res., 103, 10003-10015, doi: 10.1029/97JB03513. [Link]

Seno, T. and T. Yamasaki, 2003: Low-frequency tremors, intraslab and interplate earthquakes in Southwest Japan - from a viewpoint of slab dehydration. Geophys. Res. Lett., 30, doi: 10.1029/2003GL018349. [Link]

Shin, T.-C., C.-H. Chang, H.-C. Pu, H.-W. Lin, and P.-L. Leu, 2013: The Geophysical Database Management System in Taiwan. Terr. Atmos. Ocean. Sci., 24, 11-18, doi: 10.3319/TAO.2012.09.20.01(T). [Link]

Sibuet, J.-C., J. Letouzey, F. Barbier, J. Charvet, J.-P. Foucher, T. W. C. Hilde, M. Kimura, L.-Y. Chiao, B.
Marsset, C. Muller, and J.-F. Stéphan, 1987: Back arc extension in the Okinawa Trough.J. Geophys. Res., 92, 14041-14063, doi: 10.1029/JB092iB13p14041. [Link]

Sibuet, J.-C., B. Deffontaines, S.-K. Hsu, N. Thareau, J. P. Le Formal, and C.-S. Liu, 1998: Okinawa trough backarc basin: Early tectonic and magmatic evolution. J. Geophys. Res., 103, 30245-30267, doi: 10.1029/98JB01823. [Link]

Tarasov, V. G., A. V. Gebruk, A. N. Mironov, and L. I. Moskalev, 2005: Deep-sea and shallow-water hydrothermal vent communities: Two different phenomena? Chem. Geol., 224, 5-39, doi: 10.1016/j.chemgeo.2005.07.021. [Link]

Teng, L. S., 1996: Extensional collapse of the northern Taiwan mountain belt. Geology, 24, 949-952, doi: 10.11 30/0091-7613(1996)024<0949:ECOTNT>2.3.CO;2. [Link]

Tsai, C.-H., 1999: Submarine Volcanoes and Hydrothermal Circulation in the Southernmost Part of Okinawa Trough: An Initial Study. Master Thesis, Institute of Earth Sciences, National Taiwan Ocean University, Keelung, Taiwan, 92 pp. (in Chinese with English abstract)

Walker,G.P.L., 1989: Gravitational(density) controls on volcanism, magma chambers and intrusions. Aust.J. Earth Sci., 36, 149-165, doi: 10.1080/08120098908729479. [Link]

Wessel, P. and W. H. F. Smith, 1998: New, improved version of generic mapping tools released. Eos, Trans. $A G U, 79,579$, doi: 10.1029/98EO00426. [Link]

Wu, W.-N., L. Zhao, and Y.-M. Wu, 2013: Empirical relationships between aftershock zone dimensions and moment magnitudes for plate boundary earthquakes in Taiwan. Bull. Seismol. Soc. Am., 103, 424-436, doi: 10.1785/0120120173. [Link]

Wu, Y.-M., C.-H. Chang, L. Zhao, T.-L. Teng, and M. Nakamura, 2008: A comprehensive relocation of earthquakes in Taiwan from 1991 to 2005. Bull. Seismol. Soc. Am., 98, 1471-1481, doi: 10.1785/0120070166. [Link]

Zhao, D., O. P. Mishra, and R. Sanda, 2002: Influence of fluids and magma on earthquakes: Seismological evidence. Phys. Earth Planet. Inter., 132, 249-267, doi: 10.1016/S0031-9201(02)00082-1. [Link] 